\title{
O LUGAR DA LIBERDADE NA POLIS: UMA BREVE LEITURA A PARTIR DA "POLÍTICA" DE ARISTÓTELES
}

\author{
THE PLACE OF FREEDOM IN THE POLIS: A BRIEF \\ COMMENT OF THE ARISTOTLE'S "POLITICS"
}

\author{
Felipe Alves da Silva* \\ Recebido: 02/2017 \\ Aprovado: 09/2017
}

\begin{abstract}
Resumo: O presente texto tem por finalidade primordial abordar o modo com que Aristóteles lida e desenvolve o problema da liberdade na esfera do debate (Polis), uma vez que ajuntarse politicamente seria uma necessidade, não havendo, então, em primeiro momento, espaço para se pensar em liberdade. Verifica-se que a teoria aristotélica expressa um modelo possível de koinonia politike que aparenta ser muito interessante, pois fornece um campo de possibilidades e garantias para a comunidade que outros modelos provavelmente não possibilitariam. É na esfera do diálogo que se tem de fato a liberdade, e esta, por sua vez, só é garantida na Polis.
\end{abstract}

Palavras-chave: Aristóteles; oikos; polis; logos; liberdade.

\begin{abstract}
The main purpose of this text is to discuss the way in which Aristotle deals with and develops the problem of freedom in the sphere of debate (Polis), since political gathering would be a necessity, in this case, leaving no space to think of freedom. It turns out that Aristotelian theory expresses a possible model of koinonia politike that appears to be very interesting because it provides a field of possibilities and guarantees for the community that other models probably could not. It is in the realm of dialogue that freedom really has itself, and this, in turn, is only guaranteed in the Polis.

Keywords: Aristotle; oikos; polis; logos; freedom.
\end{abstract}

\section{Considerações iniciais}

Aristóteles inicia a "Política" enfrentando um problema, qual seja: a cidade seria um mero ajuntamento de pessoas ao acaso ou teria ela um algo que a torne necessária? A necessidade, aqui, pode ser tomada no sentido ontológico, ou melhor, a necessidade ontológica de algo. Nesse sentido, busca contrapor o argumento em contrário dos Sofistas, que defendiam o caráter contingente da formação da cidade, consistindo em um ajuntamento por mera conveniência das pessoas.

Já ao início da obra, Aristóteles supera o debate com os Sofistas, uma vez que traz a noção de que a cidade seria um algo por natureza, ou seja, a cidade não seria um mero ajuntamento de pessoas, mas organizarse politicamente seria uma necessidade, não podendo, então, ser de forma diferente. Dentro dessa perspectiva, a política se daria no âmbito da obrigação, da imposição. Assim sendo, agir politicamente não seria um ato livre, mas sim um ato imposto, um ato necessário. Ora, surge, então, um novo problema, qual seja: se há uma necessidade da política, e se a vida na Polis é necessária, onde e como pensar a liberdade? Qual o lugar da liberdade na política?

\footnotetext{
* Graduando em Direito pela Faculdade Cidade Verde (FCV) e Filosofia pela Universidade Estadual de Maringá (UEM). E-mail: felipealves silva@yahoo.com

Problemata: R. Intern. Fil. v. 8. n. 3 (2017), p. 209-227 ISSN 2236-8612 doi:http://dx.doi.org/10.7443/problemata.v8i3.33080
} 
Nesse sentido, agir politicamente não é um ato livre, mas sim um ato imposto, tal como os seres humanos ao se alimentar, isto é, querendo ou não, é necessário se alimentar - seja alimento bom seja ruim - para sobreviver. $\mathrm{O}$ ato de se alimentar se dá no âmbito da necessidade e não da liberdade, e o que há de liberdade nessa ação é a escolha dos alimentos a serem ingeridos e o modo de se alimentar, mas ter de se alimentar para não morrer não é uma ação que envolve escolha. Ora, com a afirmação de Aristóteles, ocorre praticamente a mesma coisa na política, surgindo toda uma nova problemática que o autor terá de dissertar e resolver no decorrer de sua obra.

Partindo de uma análise interpretativa da "Política", ainda que não haja qualquer pretensão de esgotamento da discussão, é justamente do ponto ressaltado que deriva a problemática a ser minimamente analisada no presente trabalho, qual seja, analisar o percurso de como Aristóteles irá pensar a liberdade no âmbito da política se esta última se dá de forma necessária, uma vez que, em tese, se for de fato necessária, não haveria liberdade, pois se dá no âmbito da obrigação.

\section{A Polis por natureza}

Jean-Pierre Vernant, em "Mito e pensamento entre os gregos", mostra que havia noções míticas que antecederam o pensamento político, mas que já demarcavam esse campo, ou melhor, que já havia uma espécie de quadro de conceituação na mitologia grega que preparou, de certa maneira, o terreno para a reflexão política. Nesse ponto, o autor chama a atenção que já estava presente no mundo helênico, na forma mítica, a distinção entre a esfera do oikos, representado na figura de Héstia, o ponto fixo da casa, e a esfera da Polis, na figura de Hermes (cf. VERNANT, 1990, p. 191). Todavia, há um momento de transição - e esse é o ponto central em que o mítico é substituído pela esfera do debate, do uso do logos, e é propriamente essa esfera que Aristóteles irá propriamente se atentar em toda sua obra "Política".

Nas linhas iniciais da obra, Aristóteles chama a atenção para o fato de que a cidade seria uma espécie de koinonia, não consistindo, então, em mero território, etnia e assim por diante, não podendo ser definida propriamente segundo determinações externas a ela. Além disso, traz a noção de que toda koinonia "é constituída em vista de algum bem" e, sendo assim, "a comunidade mais elevada de todas e que engloba todas as outras visará o maior de todos os bens" ( $P$ ol 1252a5), comunidade esta que, como já citado, é um algo por natureza. 
Ora, estabelecendo a cidade como por natureza, tem-se a noção de que essa koinonia é necessária, contrapondo ao argumento dos sofistas de que a cidade era mero acaso, ou seja, de que as pessoas se ajuntavam contingentemente, pelo acaso. Então, para rebater o argumento sofístico, Aristóteles introduz a cidade como algo necessário, fazendo todo um trabalho de justificação logo ao início de sua obra. Nesse sentido, a cidade perfaz um processo natural, consistindo no ponto final de um processo que se inicia com a junção entre o macho e a fêmea, que se unem por necessidade, com vistas a um fim, e não por mero acaso.

Aliás, não se trata de um ajuntamento por afinidade, mas sim de uma questão biológica, em que há a união para a sobrevivência, de manutenção da espécie. Assim como o as famílias que se unem em aldeias para a própria sobrevivência, a Polis surge não como mero artifício, mas um algo que se forma naturalmente, não havendo, portanto, liberdade quanto a essa necessidade de formação de uma comunidade.

\begin{abstract}
A cidade [...] é uma comunidade completa, formada a partir de várias aldeias e que, por assim dizer, atinge o máximo de auto-suficiência. Formada a princípio para preservar a vida, a cidade subsiste para assegurar a vida boa. É por isso que toda cidade existe por natureza, se as comunidades primeiras assim o foram. A cidade é o fim destas, e a natureza de uma coisa é o seu fim, já que, sempre que o processo de génese de uma coisa se encontre completo, é a isso que chamamos a sua natureza [...]. Além disso, a causa final, o fim de uma coisa, é o seu melhor bem, e a auto-suficiência é, simultaneamente, um fim e o melhor dos bens. Estas considerações evidenciam que uma cidade é uma daquelas coisas que existem por natureza e que o homem é, por natureza, um ser vivo político. ( $P o l$ 1252b30-1253a)
\end{abstract}

Ao definir aquilo que seria propriamente por natureza, no Livro II, Aristóteles passará a dissertar sobre os diferentes modos de regimes que existem, passando em revista um a um, constituição por constituição, até chegar propriamente ao Livro III, que tratará acerca do cidadão ou o político (по入ítns).

\title{
O critério para a definição do politikon
}

O filósofo inicia o livro III da obra "Política" apresentando que o ideal seria analisar os regimes, visto que o regime antecede o indivíduo, ou seja, só é possível dizer que determinado indivíduo é ateniense, porque existe Atenas, por exemplo, e inexistindo ela, não haveria ateniense. Se não 
existisse a Polis, não haveria o zoon politikon. Assim, o que existe é o regime, e estudar a política é estudar o regime.

Todavia, destaca que em primeiro momento não percebemos claramente o regime, mas o que se verifica são os indivíduos, os políticos. Dessa forma, propõe usar a mesma metodologia das ciências - que seria partir do particular ao universal - analisando a partir do político para chegar à noção do que seria o regime, ou melhor, para chegar a uma definição de cidade, Aristóteles trabalhará, antes, a definição de cidadão ${ }^{1}$ (по入ítns), como fica evidente na seguinte citação:

Em primeiro lugar, a natureza da cidade é, hoje em dia, uma questão disputada. Enquanto uns afirmam que não foi a cidade que praticou este ou aquele acto, outros afirmam que não foi a cidade, mas sim a oligarquia ou o tirano. Por outro lado, vemos que toda a actividade do político e do legislador está obviamente relacionada com a cidade. Em suma, um regime político resulta de um certo modo de ordenar os habitantes da cidade. A cidade é, pois, uma realidade composta, da mesma maneira que o são todas as outras coisas que, não obstante possuírem diferentes partes, formam um todo composto. Torna-se evidente, portanto, que devemos começar por orientar o nosso estudo para o cidadão, visto que uma cidade é, por assim dizer, um composto de cidadãos. Nesse sentido, cabe-nos considerar, então, quem deveria ser chamado cidadão, e o que é um cidadão. ( $P o l$ 1274b35)

Ora, para responder à pergunta de quem deveria ser chamado político ou até mesmo em que consistiria esse político, Aristóteles procede por eliminação de critérios, ou melhor, apresenta o que não é para, posteriormente, chegar a um critério próprio para a definição do político (то入ítns), partindo do negativo para o positivo, descartando, de início, o critério da territorialidade, uma vez que "nenhum indivíduo é cidadão só porque habita num determinado lugar, pois, tal como os cidadãos, também os metecos e os escravos possuem um local para habitar" ( $P$ ol 1275a5).

Dentro dessa perspectiva, a residência no território não seria um critério suficiente, justamente pelo fato de que os estrangeiros e os escravos também poderiam possuir esse direito. Elimina-se, então, o critério da territorialidade. O direito de acusar alguém ou de se defender de uma acusação em um litígio também não poderia ser usado como critério, porque essa prerrogativa poderia ser assegurada aos estrangeiros mediante uma espécie de tratado ou convenção (Pol 1275a10). Os estrangeiros, por exemplo, não são desprovidos de direitos, mas não poderiam se enquadrar no critério de um político em sentido completo, de um ideal. Consistiriam, então, em uma espécie de político imperfeito ou incompleto ( $\mathrm{Pol} 1275 \mathrm{a15})$. Ora, as crianças seriam políticos incompletos, 
pois ainda não estariam aptas ou capazes de exercer aquilo que é próprio do político, ou do campo da política. Os anciãos, por sua vez, não mais poderiam exercer as funções do político justamente pelo avançar a idade e assim por diante. Ambos dizem respeito a um político - incompleto ou emérito -, mas que não são no sentido absoluto do termo, e é justamente isso que Aristóteles busca, isto é, "definir o cidadão em absoluto, ou seja, aquele cidadão que não é desqualificado por nenhuma das deficiências que já vimos" (Pol 1275a20).

Nessa linha, logo em seguida apresenta o seguinte critério para a definição do político: "Ora, não há melhor critério para definir o que é o cidadão, em sentido estrito, do que entender a cidadania como capacidade de participar da administração da justiça e no governo" (Pol 1275a22).

Dentro dessa análise, a vida ou ação política seria tomada como a capacidade do indivíduo de participar das magistraturas - ou cargos administrativos - e das decisões do governo. É esse o critério para possuir o estatuto de político, e o sujeito que o detém possui, então, cidadania, é possuidor de estatuto político. O по入ítns está envolvido e participa da vida na cidade, ficando evidente, por isso, a necessidade de haver a participação na Polis. Possui, portanto, "o direito de participar nos cargos deliberativos e judiciais da cidade" ( $P$ ol 1275a32).

É justamente por esse fato que o ideal não seria traduzir o termo по入ítns por "cidadão", porque a definição ou critério apresentado aparenta ser bem mais amplo que a cidadania, visto que o sujeito poderia ser cidadão, mas ainda assim não ser político, ter estatuto político, isto é, ter tempo para exercer o direito de participar dos cargos administrativos - agir propriamente no âmbito da Polis -, bem como de fazer uso do logos e discursar ou deliberar na esfera pública. Se faz necessário, aqui, retornarmos a uma passagem em que Aristóteles delimita, nas linhas iniciais, aquilo que é próprio do bios politikon, a palavra, que o difere propriamente dos outros animais.

A razão pela qual o homem, mais do que uma abelha ou um animal gregário, é um ser vivo político em sentido pleno, é óbvia. A natureza [...] não faz nada ao desbarato, e só o homem, de entre todos os seres vivos, possui a palavra. Assim, enquanto a voz indica prazer ou sofrimento, e nesse sentido é também atribuído de outros animais (cuja natureza também atinge sensações de dor e de prazer e é capaz de as indicar) o discurso, por outro lado, serve para tornar claro o útil e o prejudicial e, por conseguinte, o justo e o injusto. (Pol 1253a7-1253a14)

Essa relação entre discurso (logos) e voz (phoné) é de suma importância para se pensar a esfera da Polis, e nos atentaremos para ela 
no decorrer da exposição. Seguindo adiante, então, o sujeito não é político porque descende de família de políticos, mora em determinado lugar, por causa das qualidades ou virtudes e assim por diante, mas por participar efetivamente da esfera pública. E, uma vez definido o político em particular, pode-se, doravante, buscar definir a Polis. Em geral, tenta-se definir a cidade a partir de um critério territorial, e pela definição do político fica evidente que Polis não é um território, mas sim a comunidade na qual as pessoas participam e deliberam sobre as decisões que a envolvem. À vista

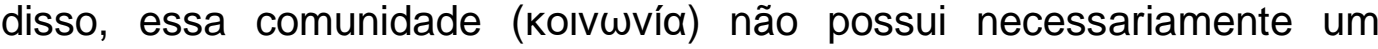
território fixo, e este, por sua vez, só pode ser estipulado a partir da comunidade. Sendo assim, o limite territorial de qualquer que seja a comunidade política seria dado a partir do alcance da atividade política dessa mesma comunidade. Ora, assim sendo, é o regime que fornece a pauta para pensar a quantidade de políticos que determinada koıvwvía terá, por exemplo.

Com base nos apontamentos anteriores, é razoável ainda se perguntar sobre o que ocorreria com os contratos firmados durante a vigência de determinado regime caso houvesse uma transição, ou, mais ainda, caso houvesse uma transição de regime, a cidade iria adquirir uma identidade diferente ou manteria a mesma identidade? Seguindo a argumentação apresentada, fica evidente que apesar da mudança, a identidade se manteria, visto que o regime seria um composto de políticos, isto é, a identidade dessa determinada comunidade (koıvwvía) política se manteria, porque só podemos pensar em regime a partir dos políticos que o compõe. Isso fica explícito na seguinte passagem:

Se a cidade é uma forma de comunidade (e uma comunidade de cidadãos num regime) quando se altera a forma de governo, ficando diferente do que estava, parece forçoso que a cidade deixe de ser a mesma, tal como dizemos de um coro que é uma coisa quando é cómico e é outra quando é trágico, apesar de os seus membros permanecerem os mesmos. Também dizemos que uma comunidade ou unidade composta é distinta, quando muda a forma de sua composição. A harmonia composta pelas mesmas notas será diferente consoante o modo seja dório ou frígio. Se este é o caso, é óbvio que o critério para determinar a identidade da cidade é o critério do regime, podendo-se-lhe atribuir um nome idêntico ou outro nome, quer tenha os mesmos habitantes ou outros totalmente diferentes. ( $P o / 1276 b)$

Por fim, pode-se dizer que a definição do político presente no início do livro III segue o modelo aristotélico de partir do negativo para o positivo, ou por exclusão, argumentando, em primeiro momento, que em geral se diz que aquele que descende de político possui o estatuto de político. Além 
disso, ressalta que a condição política não é dada pelo critério da territorialidade e nem pelo da hereditariedade, até chegar ao critério próprio do político, que seria a "capacidade de participar na administração da justiça e no governo" ( $P o l$ 1275a22), ou seja, participar das magistraturas cargos administrativos -, bem como ter tempo de deliberar e exercitar o logos na esfera pública. A finalidade é, portanto, apresentar o primeiro critério - que seria o qualitativo - para analisar o regime, consistindo propriamente na ação política, pois seria através dela que se chega ao regime. Doravante, a partir do livro III, Aristóteles buscará estabelecer os critérios para se pensar os regimes, que seria o critério da qualidade e o da quantidade.

O percurso aristotélico é interessante, pois uma vez definido o que é o político, ele poderá, passo seguinte, deixar claro o que define o bom homem e o bom político, ou melhor, qual a diferença entre o phronimos e o то入і́тns. Nesse ponto, Aristóteles argumentará que não é necessário que o político seja um phronimos, ou seja, ele não precisa ser um virtuoso, um excelente, um sujeito dotado dos mais elevados grau de virtude. Pelo contrário, basta que ele detenha uma virtude somente, a saber: obedecer às leis da cidade. Todavia, ainda que não diz que o governante deveria ser um phronimos, é obvio que para governar o político necessita de algumas virtudes, como no caso de um general, que precisa ter algo para além da virtude de um soldado. Aristóteles demarca, portanto, o que seria próprio de cada campo, diferenciando o âmbito público do âmbito privado, ou seja, o que é próprio do oikos e o que é próprio da vida na Polis.

\section{Politeia mixis meson: o regime possível}

Feita a demarcação demonstrada anteriormente, pode-se pensar, agora, quais seriam os critérios para se pensar os regimes, e é justamente o que Aristóteles buscará fazer a partir do livro terceiro. Desse modo, ressalta que podemos pensar os regimes a partir de dois critérios, a saber: o critério da qualidade e o da quantidade. Do ponto de vista deste último, o regime pode ser governado por um indivíduo, por alguns ou, também, por muitas pessoas. Do ponto de análise qualitativo, o regime pode ser classificado como visando o interesse próprio ou se visa o interesse de todos.

Ora, seria a partir da combinação desses dois critérios que será estabelecido as formas de governo, que podem ser seis diferentes formas. Quando se combina o critério de um só governando por interesse próprio, dá-se o nome de tirania; um só governando para muitos, chama-se 
monarquia ou realeza. Quando alguns visam o interesse próprio, oligarquia; quando alguns visam o interesse de todos, tem-se a aristocracia. Quando muitos governam sob o interesse próprio, denomina-se democracia; e quando muitas pessoas governam sob o interesse comum, tem-se o que Aristóteles chama de Politeia².

São seis formas de governo, porque tratam da combinação de dois critérios de qualidade com os três de quantidade. O interessante, aqui, é que o que faz Aristóteles estabelecer essas seis formas de governo não são aquelas formas que estão no mundo, mas se tratam de dois modelos teóricos abstratos que, como já colocado, a partir de uma análise combinatória matemática, estabelece as seis formas de governo. Portanto, essas formas apresentadas no livro terceiro que se trata como uma teoria das formas de governo é fruto de um critério matemático e teórico para se pensar o regime. Teríamos, então, no livro III, a definição do que seria o eidos, ou melhor, a forma, a ideia do regime.

A despeito da importância do livro terceiro e a transição para o livro quarto, Martins (2010, p. 16-17) ressalta:

\begin{abstract}
Após ter mostrado a natureza de cada uma das formas particulares de governo no livro III, seis concepções derivadas da combinação de um critério de qualidade (retidão e desvio) e da quantidade (governo de um só, de alguns e de muitos) [...], Aristóteles se detém, no livro IV, a considerar qual a forma de governo mais adequada, não mais tratando de aspectos teóricos, mas levando em conta apenas os regimes efetivamente existentes. No livro III, o objetivo é analisar o que é o regime (to esti politeias), e não qual a melhor forma de regime realmente existente ou possível de se efetivar, tema do livro IV. [...] $\mathrm{Na}$ verdade, trata-se de analisar no livro IV qual o melhor regime para os diversos tipos de cidade, ou seja, pensar o regime político não em função daquilo que seria melhor conceitualmente falando-se, mas em conformidade com aquilo que se encontra em cada cidade [...]. Verificase, então, uma transição na argumentação aristotélica do livro III para o livro IV, ou seja, não se trata apenas de analisar a forma excelente, nem aquela que seja mais comum ou universal para toda e qualquer polis, mas sim, de pensar em uma "ordenação política [taxis politeia] cujas disposições persuadam facilmente os cidadãos e facilmente sejam adotadas" [...].
\end{abstract}

Ora, como bem pontuou Martins (2010, p. 17), se o texto terminasse nesse ponto, não haveria qualquer aplicabilidade, pois a finalidade é justamente estipular a ideia para se pensar o regime. Aliás, cumpre ressaltar que depois de apresentar a teoria das formas de governo, o filósofo começa a analisar diversas questões, mas ainda assim do ponto de vista teorético, como a questão das leis, por exemplo. Trata-se de apenas 
um modelo teorético para se pensar o direito e não uma lei de fato. Posteriormente, no livro IV, Aristóteles reconhece que possui o critério teórico, restando, agora, saber qual seria de fato o melhor regime para a cidade, como fica evidente na seguinte passagem:

Para além de tudo isto, caberá a essa ciência conhecer a forma de regime que melhor convém ao conjunto de todas as cidades, dado que a maioria daqueles que aplicam os seus pontos de vistas a um regime, e por mais belos que sejam os seus argumentos, fracassam em termos de utilidade prática. (Pol 1288b30)

Poder-se-ia dizer que há uma crítica ao modelo platônico, que parte do pressuposto de modelos ideais que fracassaram quando se tentou transportar para a realidade, porque o procedimento teórico - partir de uma ideia para a aplicação - está equivocado. Nesse sentido, continua Aristóteles:

Significa isto que não devemos contemplar apenas o melhor regime mas também aquele que é simplesmente possível, ainda aquele que é de mais fácil aplicação e mais comum a todas as cidades. A verdade é que grande parte dos autores procuram apenas a forma mais excelente e que requer abundância de recursos; outros propõem uma forma comum para todas as cidades, menosprezando os regimes já estabelecidos, e exaltando, por exemplo, a constituição espartana ou outra qualquer. (Pol 1288b35)

É justamente essa a finalidade, ou seja, verificar um regime que seja "simplesmente possível", alcançável, atingível (cf. MARTINS, 2010, p. 18). Ora, quando fala do que é possível, Aristóteles se volta para a realidade, isto é, uma sociedade que não é em sua totalidade formada por virtuosos, mas sim por pessoas com defeitos, vícios e assim por diante.

\section{A liberdade na necessidade: o fim do percurso aristotélico}

Se, como expressado, no livro III Aristóteles tratou do eidos, então no livro IV ele buscará tratar a respeito do hipokeimenon, ou melhor, o substrato material da cidade, que seriam as pessoas. Assim, tendo em vista que a cidade é composta por uma grande diversidade, Aristóteles irá separar a cidade em dois grandes grupos ou critérios: o critério da riqueza (oligarquia) e o critério da liberdade (democracia).

Nesse ponto, cumpre ressaltar que ser rico, aqui, não significa ter dinheiro, mas sim deter mercadorias para trocar e assim por diante. Isso 
leva a um problema, pois para possuir coisas para trocar era preciso haver a dedicação exclusiva do indivíduo a essa finalidade, não sobrando tempo para se envolver em quaisquer outras questões. Nesse caso, quem seria, portanto, detentor de liberdade? Ora, seria justamente aquele que não tem tantas mercadorias para trocar e administrar. Significa dizer que quem tem mais dinheiro, não tem tempo, e, portanto, não tem liberdade. Assim sendo, ter liberdade é estar desvinculado às necessidades materiais, pois se determinado sujeito ter um oikos com vários escravos, por exemplo, teria de se dedicar exclusivamente a isso, uma vez que haveria uma enorme quantidade de coisas para administrar. É interessante esse ponto, porque retorna à questão do moגítns, nos fazendo indagar o motivo de alguns não poderem participar da esfera pública, que seria justamente o fato de não ter tempo para deliberar e participar ativamente dos cargos administrativos.

Dentro da perspectiva analisada, percebe-se que Aristóteles demarca o que é próprio da vida na Polis e o que é próprio da vida no oikos, isto é, coloca em evidência que haveriam duas formas de vida antagônicas entre si, qual seja: a vida meramente biológica (zoé), que diz respeito ao zoon politikon, e a vida propriamente política (bíos), o bíos politikos Nessa linha, ainda que não seja propriamente o objeto do presente trabalho aprofundar ou tratar propriamente de seu pensamento político, Hannah Arendt (2007, p. 33) argumenta o seguinte:

\begin{abstract}
A companhia natural, meramente social, da espécie humana era vista como limitação imposta pelas necessidades da vida biológica, necessidades estas que são as mesmas para o animal humano e para outras formas de vida animal. Segundo o pensamento grego, a capacidade humana de organização natural cujo centro é constituído pela casa (oikia) e pela família. O surgimento da cidade-estado significava que o homem recebera, «além de sua vida privada, uma espécie de segunda vida, o seu bíos politikos. Agora cada cidadão pertence a duas ordens de existência; e há uma grande diferença em sua vida entre aquilo que lhe é próprio (idion) e o que é comum (koinon)».
\end{abstract}

O tempo livre, que significa liberdade, diz respeito, então, a uma certa desvinculação das questões materiais, em que o indivíduo não fica preso às necessidades materiais. Contudo, vale pontuar que é preciso que haja uma mediania, pois tanto o grande detentor de mercadorias quanto o pobre em demasia poderão ter posturas extremadas, seja pelo desconhecimento do debate por não participar continuamente seja por quaisquer outras questões.

Nesse sentido, será preciso, então, excluir e descartar os excessos para, passo seguinte, pegar os setores medianos nos quais será 
estabelecido o governo. Nesse sentido, é preciso recorrer à mediania para eliminar os extremos, porém, é preciso nos perguntarmos como é realizada a seleção daquilo que é mediano. Para tanto, é preciso primeiramente fazer uma divisão quantitativa e qualitativa e usar somente o que diz respeito ao setor mediano. Ainda assim, como compor esses setores? Ora, esses setores têm de ser compostos a partir de um critério proporcional, logo, numérico ${ }^{3}$. A finalidade é buscar um certo equilíbrio, tentando sempre diminuir o domínio de determinado setor com um valor discrepante de pessoas com relação aos outros.

Essas pessoas irão dirigir a cidade por um tempo determinado, e quando saírem isso não significa necessariamente que o indivíduo deixará de ser o que é, ou seja, o oligarca não deixará de ser oligarca, e nem o democrata deixará de ser democrata, por exemplo. Todavia, ainda que deixe de ser, o democrata nunca será tão rico e nem o oligarca será tão pobre. A mediania ${ }^{4}$ garante que, ainda que ocorra uma inversão, os extremos não são sejam possíveis, isto é, continua mesmo assim nos setores medianos. Dessa forma, percebe-se que é a parcela mediana que governa, uma vez que é esse setor o mais relevante, o mais estável, pois se mostra como o mais expressivo e representativo.

Retornando à questão do regime, pode-se dizer que Aristóteles busca propor um modelo de regime altamente flexível e possível, haja vista que leva em consideração o que existe no mundo e as inúmeras diversidades que trazem consigo. Um regime pode, em determinada circunstância, funcionar ou não, bem como as pessoas podem variar migrando da riqueza para a pobreza e assim por diante, sendo necessário mudar a proporção. O critério aristotélico é, portanto, flexível, e por ser assim, pode ser aplicado em toda e qualquer cidade, não do ponto de vista da ideia, mas sim da realidade, do hipokeimenon da cidade. Contudo, é preciso ressaltar que a cidade é muito mais complexa e Aristóteles pega os dois critérios que mais estão em evidência, que é o da liberdade e o da riqueza, isto é, quando se volta para a Polis percebe-se que há "um grupo diminuto e rico, mas sem liberdade, a oligarquia; e um grupo maior, não possuidor de riqueza e dotado de liberdade, a democracia" (MARTINS, 2010 , p. 18). Aliás, Martins ainda chama a atenção para o fato de que, nesse ponto, os termos democracia e oligarquia "não dizem respeito a regime político, mas aos segmentos políticos predominantes em toda e qualquer cidade" (MARTINS, 2010, p. 18).

A democracia em si é um governo ruim assim como qualquer forma de governo em si mesma. O único que não é ruim em si mesmo é a aristocracia, tendo em vista que leva em conta a virtude, e se ela é o elemento predominante, trata-se de um modelo perfeito ou ideal. Todavia, 
apesar de ser a forma de governo mais adequada, não se trata de um regime possível. Sobre isso, Martins continua:

\begin{abstract}
Em vista da dificuldade presente na instalação de um regime aristocrático, conceitualmente o melhor, a solução é a fundação de um regime que congregue proporcionalmente as parcelas democrática e oligárquica da polis, ou seja, um regime que seja uma mistura proporcional de liberdade e riqueza. Como essa proporcionalidade é relativa ao substrato material da cidade, no caso, o regime deve expressar as mesmas proporções relativas do total de democracia e de oligarquia; portanto o governo (politeia e eidos da polis) deve espelhar proporcionalmente as quantidades de homens livres (democratas) e ricos (oligarcas) que compõe esse substrato material da polis, logo não tem uma conformação única e restrita, mas diversa conforme a diversidade dos substratos materiais das cidades. (MARTINS, 2010, p. 19)
\end{abstract}

Portanto, tirando o modelo da aristocracia, todos os demais são ruins, haja vista que dizem respeito ao particular. Nesse sentido, a mistura (mixis) que Aristóteles se refere não está relacionada a essas formas ruins, mas sim de dois modelos que existem. Se se leva os interesses de cada um em particular, ocorre o desvirtuamento do regime, e é justamente para que isso seja evitado que é preciso misturar. Essa mistura não é, então, uma escolha, mas sim uma solução possível e racional - que envolve certa ponderação - para que o regime perdure.

Aristóteles ressalta que se só haver leis iguais ao modelo democrático, haverá a punição em excesso do oligarca, porque é da natureza do democrata agir e pensar como um democrata. Essa mistura surge para garantir certa representação, ou seja, é preciso que haja certos grupos na esfera pública que represente o seu setor. $O$ democrata não se coloca na posição de um oligarca, e vice-versa, por isso se faz necessário ter os dois na esfera da discussão pública para haver deliberação.

O papel do oligarca na elaboração da lei é de suma importância, pois exerce uma espécie de contrapeso, impedindo o excesso e freando o desejo desmedido do democrata por intermédio do debate. É o contraponto e o contraditório que combate o excesso, por isso é necessário que haja essa mistura. Ela é uma imposição no sentido de tentar promover que o governo perdure. É fundamental e necessário que haja essa contraposição.

De resto, fica evidente que será necessário um elemento dirigente que seja expressivo desse hipokeimenon, e que na sua composição perfaz o regime mais equilibrado. A moderação é a marca. Há, portanto, em Aristóteles, seis formas de governo teoréticas, mas somente uma forma de governo possível na prática, saber: um regime que mistura as partes 
medianas, ou, nos termos aristotélicos, politeia mixis meson. Com base no exposto, poderiam argumentar que, em tese, haveriam sete formas de governo em Aristóteles, mas na realidade são seis formas teoréticas e só uma de fato possível.

Ainda que não seja propriamente o objeto do presente trabalho, esse ponto é interessante, pois poderíamos dizer que o modelo da tirania, por exemplo, anula o campo do político, isto é, por mais contraditório que possa aparentar, é uma forma de governo que anula o campo próprio do político, uma vez que o tirano, ao impor a sua vontade, anula justamente o que caracteriza o político, a saber, a isegoria e a isonomia, violando-as. Se mostra, assim, como a negação do campo do político.

Voltando ao regime possível, há a afirmação de duas coisas essenciais para o campo do político: um campo que é aberto, ou seja, permite que as pessoas participem e, ao mesmo tempo, as pessoas têm de estar presentes na esfera pública. Desse modo, há uma bi-implicação da noção de participação, em que por um lado ela é aberta e por outro ela faz com que seja uma obrigação interagir no campo político. Nesse sentido, a isegoria e a isonomia serão necessárias, porque a lei não poderá privilegiar um setor em face do outro e assim por diante.

É preciso chamar atenção para o fato de que isonomia não significa necessariamente direitos iguais, pois não seria justo tratar igualmente os desiguais, mas sim tratar igualmente os iguais e desigualmente os desiguais na medida de sua desigualdade. A justiça se encontra na proporcionalidade da lei. Com isso, se o regime for proporcional ele produzirá uma lei justa, ou seja, proporcional, que estabeleça uma calibragem igual. A isonomia nasce de um regime político que se percebe de modo equilibrado, mas naturalmente desproporcional, em que caso haja a inversão da proporção, é preciso inverter e alterar a lei, continuando isonômico. A lei se altera, mas não se perde a isonomia.

Aquilo que é próprio do político, ou melhor, o que caracteriza o agir e a vida política é o aprimoramento do discurso (logos), que se realiza tãosomente no âmbito público. Agir politicamente é, portanto, mostrar-se ou fazer-se visível na esfera pública e, não obstante, é na esfera pública que se tem de fato a liberdade. De certa forma, poderíamos dizer que política e liberdade se mostram, portanto, como sinônimos. Isso caracteriza, por sua vez, um dos dados fundamentais da isegoria, que não diz respeito a somente discursar ou enunciar determinado argumento, mas ao ato de tomar posição na esfera pública, ou seja, aquele que discute e delibera. Nessa linha, о то入ítns age politicamente quando argumenta, faz uso do logos, e é detentor de liberdade uma vez que age na esfera pública. 
Na experiência da polis que, com alguma razão, tem sido considerada o mais loquaz dos corpos políticos, e mais ainda na filosofia política que dela surgiu, a ação e o discurso separaram-se e tornaram-se atividades cada vez mais independentes. A ênfase passou da ação para o discurso, e para o discurso como meio de persuasão não como forma especificamente humana de responder, replicar e enfrentar o que acontece ou o que é feito. O ser político, o viver numa polis, significava que tudo era decidido mediante palavras e persuasão, e não através de força ou violência. Para os gregos, forçar alguém mediante violência, ordenar ao invés de persuadir, eram modos pré-políticos de lidar com as pessoas, típicos da vida fora da polis, característicos do lar e da vida em família, na qual o chefe da casa imperava com poderes incontestes e despóticos, ou da vida nos impérios bárbaros da Ásia, cujo despotismo era frequentemente comparado à organização doméstica. (ARENDT, 2007, p. 35-36)

No que concerne a essa questão de que o que regia a esfera privada (oikos) era a necessidade e a esfera pública (Polis) era a liberdade, Hannah Arendt consegue sintetizar de forma muito significativa esse ponto, em uma passagem de "A condição humana", argumentando que a necessidade reinava sobre "todas as atividades exercidas no lar. A esfera da polis, ao contrário, era a esfera da liberdade, e se havia uma relação entre essas duas esferas era que a vitória sobre as necessidades da vida em família constituía a condição natural para a liberdade na polis" (ARENDT, 2007, p. 40). No oikos não há o desenvolvimento do logos, mas sim phoné (voz), tendo em vista que somente a Polis proporciona o exercício e, não obstante, o aprimoramento do discurso.

Ora, é do exercício do discurso na esfera pública que deriva a noção apresentada por Jean-Pierre Vernant (1990, p. 476) de que a filosofia é a filha da Polis e esta, por sua vez, é a filha da filosofia, porque o argumento é que permite se criar a filosofia, significa dizer, essa prática discursiva no âmbito da cidade é que permitiu a criação da filosofia e foi justamente esse discurso em praça pública que aperfeiçoou a própria reflexão do que é ou no que consiste o político e a vida política, fazendo com que houvesse interação sobre o modo de interagir enquanto comunidade política. Nas suas belíssimas palavras:

É pela elaboração de uma forma de racionalidade e de um tipo do discurso até então desconhecidos que a prática da filosofia e a figura do filósofo emergem e adquirem seu próprio estatuto; delimitam-se, no plano social e intelectual, atividades profissionais como funções políticas ou religiosas situadas na cidade, inaugurando uma tradição intelectual original que, a despeito de todas as transformações por ela sofridas, nunca cessou de se enraizar em suas origens. 
Ora, é justamente do confronto dos discursos, no ato do exercício da ação política, que nasce a "consciência" da comunidade (koinonia). É o debate que irá gerar essa consciência política, por isso precisa ser cada vez mais incentivado, somado ao fato de que é na esfera pública que há propriamente a liberdade. Sendo assim, o argumento que será gerado a partir do debate será também mediano, pois pode ter nascido de duas posições extremadas cujas posições foram aos poucos sendo calibradas por intermédio do enfrentamento de argumentos contrários. Essa discussão dará vazão a uma deliberação que, por sua vez, se transformará praticamente em um costume ou hábito da cidade, ou seja, são valores que serão construídos a partir do debate e da ponderação.

Nessa linha, a exposição aristotélica nos mostra que esse campo da necessidade - de puro determinismo e não-liberdade - vai se amalgamando e se tornando um campo de escolhas dentro de um certo quadro de possibilidades. Todavia, ainda assim determinado indivíduo pode escolher não fazer parte da vida na cidade, mas isso, dirá Aristóteles, não promoverá a eudaimonia ${ }^{5}$, pois somente a Polis promove a vida boa. As demais comunidades podem garantir a vida, mas apenas a Polis garante o тоũ घũ $\zeta \tilde{\eta} v$, isto é, a vida boa (Pol. 1252b30).

A eudaimonia é o fim das ações humanas que só pode ser alcançada quando o homem escolhe viver conforme a virtude. A virtude, por sua vez, é uma disposição para o homem agir de uma determinada maneira ( $E N$ II 6 1107a). Contudo, é errôneo tomar por eudaimonia as alegrias ou sentimentos temporais, tendo em vista que o bem a ser tratado como eudaimonia deve necessariamente ser um bem autossuficiente e mais completo, não tratando de algo tão superficial quanto um sentimento passageiro. Na realidade ela não pode nem ser equiparada aos outros bens, pois é por si mesma o bem que organiza os demais, logo, nem se conta entre eles.

Nós chamamos aquilo que merece ser buscado por si mesmo mais absoluto do que aquilo que merece ser buscado com vistas em outra coisa. [...] Ora, esse é o conceito que preeminentemente fazemos da felicidade. É ela procurada sempre em si mesma e nunca com vistas em outra coisa. [...] A felicidade é, portanto, algo absoluto e autossuficiente, sendo também a finalidade da ação. (ENI 7 1097a32)

Ainda no tocante à eudaimonia, Marco Zingano argumenta que:

A felicidade é definida como "a atividade da alma segundo a virtude" (I 6 1098a16-17). Não é, portanto, um estado da alma, mas uma 
atividade, o que remete diretamente às ações que o homem faz ou se abstém de fazer. Além do mais, a felicidade não é questão de um instante, de um fim-de-semana, mas se estende ao longo da vida (ele se realiza en biôi teleiôi, "em uma vida completa", I 6 1098a18). [...] Em particular, pode-se dissentir se se trata de uma virtude que contém a razão prática, somente a razão teórica ou uma certa dosagem de ambas; mesmo assim, é indiscutível que se trata de uma virtude na qual opera a razão, qualquer que seja sua modalidade. Enquanto virtude, por outro lado, a virtude perfeita é uma disposição, pois a disposição é o gênero da virtude, e a disposição é o modo pelo qual o homem se comporta relativamente às emoções. A felicidade é o fim último de todas as nossas ações, as ações devem ser aperfeiçoadas pela razão, mas, no início, estão as emoções. Muito da vida moral depende dos hábitos tomados em sua relação, o que não é de pouca importância; ao contrário, Aristóteles nos diz que é "de uma grande importância, ou antes: de toda importância" (II 1 1103b25), pois aqui se abre - ou se fecha - o caminho para a felicidade. (ZINGANO, 2009, p. 144-145)

Ora, Zingano destaca que a felicidade não diz respeito a um mero momento trivial, mas que só pode ser analisada a partir da perspectiva da vida completa, ou, nos termos aristotélicos, en biôi teleiôi, havendo a referência ao termo bíos e não zoé, ou seja, à vida política e não à vida meramente biológica do oikos, referindo-se à vida propriamente voltada para a esfera pública. Isso também se torna evidente quando Aristóteles nos apresenta a seguinte passagem da "Ética à Nicômaco" dizendo:

[...] o bem do homem nos aparece como uma atividade da alma em consonância com a virtude, e, se há mais de uma virtude, com a melhor e mais completa. Mas é preciso ajuntar "numa vida completa". Porquanto uma andorinha não faz verão, nem um dia tampouco; e da mesma forma um dia, ou um breve espaço de tempo, não faz um homem feliz e venturoso. (ENI 7 1098a15)

Entretanto, ainda que a eudaimonia envolva certa totalidade, seria possível analisar se determinado indivíduo pode ser considerado feliz ou não antes que perca sua vida, pois não haveria por que viver virtuosamente se só após a morte ele descobriria se alcançou ou não a felicidade (cf. EN 110 1100a35). A virtude está nas mãos das pessoas, portanto, ainda que ocorra uma desgraça muito grande o sujeito pode se recuperar e alcançar a eudaimonia.

No fim, a Polis será o reflexo do uso das deliberações, isto é, as disposições dos indivíduos serão usadas na Polis e para ela. É nela que o homem pode livremente usar e aprimorar o logos, porém ele não é necessariamente privado da possibilidade de escolha entre viver na Polis 
ou viver isoladamente, por exemplo. Há liberdade de escolha, entretanto, se é para desenvolver as virtudes em plenitude e atingir a eudaimonia, as ações só poderão ser avaliadas como sendo ou não virtuosas na medida em que são praticadas em sua totalidade na esfera do debate, porque, como bem pontua Aristóteles, por mais que o bem do sujeito seja nobre, o bem da maioria se sobrepõe.

Como a política utiliza as demais ciências e, por outro lado, legisla
sobre o que devemos e o que não devemos fazer, a finalidade dessa
ciência deve abranger as das outras, de modo que essa finalidade será
o bem humano. Com efeito, ainda que tal fim seja o mesmo tanto para
o indivíduo como para o Estado, o deste último parece ser algo maior
e mais completo, quer a atingir, quer a preservar. Embora valha bem a
pena atingir esse fim para um indivíduo só, é mais belo e mais divino
alcança-lo para uma nação ou para as cidades-estados. (EN I 2
1094b5-10)

Nesse sentido, a vida na esfera pública - do bíos politikon - é tomada como o único caminho que o homem deve seguir para ter propriamente uma vida completa, mas ainda assim é evidente que nem todos escolhem percorrer esse caminho. Então, no que se refere aos tipos de vida que se pode escolher, há a possibilidade de se escolher a vida dos prazeres - que é diretamente ligada aos apetites -, porém esse estilo de vida deve ser descartado pelo simples fato de que nele se enquadram o intemperante $^{6}$ e, também, o vicioso, não devendo ser valorizada, pois faz com que os indivíduos vivam como os animais. Em contrapartida, Aristóteles traz duas possibilidades de vida valorosa, sendo elas a vida prática, ou também denominada de vida política, e a vida de estudos, ou também contemplativa, em que tanto uma quanto a outra são "as duas formas de vida humana que parecem preferir os homens mais ambiciosos de virtude" (Pol. VII 1324a30). Ambas de certa forma se complementam diante de certa dosagem, de certa mediania.

\section{Considerações finais}

Para o pensamento helênico, portanto, não seria possível pensar a liberdade no oikos, mas só se poderia pensar de fato em liberdade na Polis. O que rege o oikos é a necessidade e, por ser assim, diz respeito à pura determinação. Todavia, nas páginas iniciais da "Política", a Polis se instaura como uma necessidade natural, no âmbito do determinismo naturalista e, nesse sentido, a dificuldade e a problemática que Aristóteles teve de 
enfrentar - da qual propusemos expor minimamente - se encontra em como se pensar a liberdade dentro desse quadro de determinismo natural, isto é, tendo em vista que a cidade é uma determinação, como seria possível, então, a liberdade? Ora, se a política é uma determinação e o lugar da possibilidade da eudaimonia, uma vez que fora dela isso não é possível, então não haveria liberdade, mas sim imposição. Essa é propriamente a finalidade da obra, significa dizer, como garantir que a política seja esse âmbito da vida que garanta a liberdade, ou seja, que garanta a isegoria e a isonomia enquanto manifestação da liberdade.

Fica evidente que o campo do político nasce, em Aristóteles, como algo que tem de ser acessível e composto pela comunidade política, não se tratando de uma imposição. Tudo isso envolve um cálculo racional, uma deliberação, e o sujeito, aqui, não é obrigado a ser um moגítns, mas só enquanto tal atingirá a vida completa, ou melhor, apenas no campo da política encontrará a eudaimonia, que também diz respeito à liberdade. Nesse sentido, não é que todos são obrigados a serem políticos e participarem das deliberações na esfera pública, pois pode haver a escolha de não o fazer, uma vez que é por natureza um animal político (zoon politikon), que pode deliberadamente optar por não ser um bíos politikon. Ser político, portanto, está no âmbito da possibilidade.

Dentro do contexto analisado, a linguagem, o exercício do logos na esfera pública tem, aqui, um papel de fundamental importância. A política passa a ser um cenário em que se faz necessário que os atores debatam e argumentem para chegar a uma deliberação sobre determinado assunto. A teoria aristotélica expressa um modelo possível de koinonia politike que aparenta ser muito interessante, tendo em vista que fornece um campo de possibilidades e garantias para a comunidade que outros modelos provavelmente não possibilitariam. É justamente nesse campo de diálogo que se tem de fato a liberdade, e esta, por sua vez, só é garantida na Polis. O lugar que escapa do determinismo naturalista paira, portanto, na esfera pública.

\section{Referências}

ARISTÓTELES. Ética a Nicômaco. In: Col. Os Pensadores. São Paulo: Abril S/A Cultural e Industrial, 1973.

Política. Tradução de Antônio Campelo Amaral e Carlos Gomes. Edição Bilíngue. Universidade Católica Portuguesa: Vega, 1998. 
ARENDT, Hannah. A condição humana. Tradução de Roberto Raposo, posfácio de Celso Lafer. - 10 ed. - Rio de Janeiro: Forense Universitária, 2007.

MARTINS, José Antônio. Da Politeia Mixis à Res Publica: notas sobre o regime misto no pensamento antigo. In: MARTINS, José Antônio (org.). Republicanismo e democracia. Apresentação de Carla Cecília Rodrigues Almeida, José Antônio Martins. - Maringá: Eduem, 2010.

VERNANT, Jean-Pierre. Mito e pensamento entre os gregos: estudos de psicologia histórica. Trad. Haiganuch Sarian. Rio de Janeiro: Paz e Terra, 1990.

WOLFF, Francis. Aristóteles e a política. Trad. Thereza Christina Ferreira Stummer, Lygia Araujo Watanabe. São Paulo: Discurso Editorial, 1999.

ZINGANO, Marco. Estudos de ética antiga. 2. ed. São Paulo: Discurso Editorial: Paulus, 2009.

\footnotetext{
${ }^{1}$ Apesar da tradução apresentar o termo "cidadão", no texto original o termo é moגítns, então o ideal seria traduzir por "político", visto que o sujeito pode ser cidadão - ter cidadania - e não necessariamente ser político. Dessa forma, em toda citação direta ou indireta no decorrer do presente trabalho em que estiver o termo "cidadão", leia-se "político".

2 Há casos em que se traduzem esse tipo de governo pelo termo "democracia", o que seria equivocado, porque a democracia, aqui, é um tipo de governo corrompido. O termo que Aristóteles traz é Politeia, que seria uma forma possível de koinonia politike.

3 Esse instrumento matemático funciona como uma espécie de calibrador, em que a medida é variável, mas não o que está calibrando. O princípio de calibrar não sofre variação, mas sim o número absoluto da calibragem que ora está para um lado ora para outro.

${ }^{4}$ A palavra "mediania" foi bem empregada nesse ponto, por isso chamo a atenção para a seguinte passagem de Martins (2010, p. 19): "[...] esse meio não é uma soma das partes que se divide pelo seu número, donde de fato teríamos uma média aritmética simples. Aristóteles fala numa parcela mediana relativa ou proposicional aos extremos que expresse o segmento médio de um grupo. Neste caso, temos uma diferença entre a média e a mediana, pois a mediana expressa um número diferente da simples média aritmética. Na verdade, essa mediania reflete a proporção que melhor representa a totalidade da cidade, coisa que a média aritmética em geral não consegue. Tal parcela mediana fornecerá ao regime maior estabilidade, pois também consegue atender às exigências de uma justiça relativa (logo, proposicional), e não absoluta".

${ }^{5}$ Ainda que alguns aristotélicos propõem que se traduza eudaimonia por felicidade, optamos por usar o termo grego não traduzido quando não se tratar de citações diretas.

6 "Intemperante seria aquele indivíduo que já parte de um "norte incorreto", isto é, tem por finalidade fazer o incorreto. Dentro dessa perspectiva, não haveria phronesis, o cálculo racional, nas decisões de um intemperante, haja vista que ela pressupõe um ponto de partida correto, uma boa escolha, uma boa ponderação, e não há intenção boa nas ações de um intemperante.
} 